\title{
A percepçáo dos profissionais sobre o brinquedo em uma unidade intermediária de um hospital de média e alta complexidade ${ }^{1}$
}

\author{
Valeria Borges Ribeiro Lima, Fernanda do Nascimento Maia, Rosa Maria de Araújo Mitre \\ Instituto Fernandes Figueira, Fundação Oswaldo Cruz - Fiocruz, Rio de Janeiro, RJ, Brasil.
}

\begin{abstract}
Resumo: Este artigo buscou investigar o brinquedo permanente como estímulo constante ao desenvolvimento global de crianças internadas em uma Unidade Intermediária de um hospital de média e alta complexidade, a partir da visão dos profissionais de saúde que atuam na unidade. A pesquisa foi realizada em um instituto nacional referência no atendimento da criança e do adolescente, localizado no Estado do Rio de Janeiro. O campo escolhido nesse instituto se deu pela sua complexidade, por atender a uma clientela com um perfil diferenciado de internação pediátrica, com a maior parte das crianças cronicamente adoecidas e dependentes de tecnologia, o que a diferencia de outras unidades intensivas pediátricas. Trata-se de uma pesquisa exploratória com abordagem qualitativa, composta por observação participante da rotina de crianças internadas em uma Unidade Intermediária (UI), com idade cronológica de zero a dois anos, e realização de entrevistas semiestruturadas com profissionais de saúde que atuavam no atendimento aos pacientes da unidade. Os achados possibilitaram discutir a importância do brinquedo permanente como recurso primordial ao desenvolvimento global durante a hospitalização infantil, contribuindo para uma possível ressignificação do modelo tradicional de intervenção e cuidado de crianças hospitalizadas.
\end{abstract}

Palavras-chave: Jogos e Brinquedos, Desenvolvimento Infantil, Criança Hospitalizada, Terapia Ocupacional.

\section{The professionals perception of the toy in an intermediary unit of a medium and high complexity hospital}

\begin{abstract}
This study sought to investigate the permanent toy as a constant stimulus to the overall development of children hospitalized in a intermediary unit of a medium and high complexity hospital, from its professionals point of view. The method is characterized by a qualitative approach, consisted of the parcipatory observation of hospitalized children routine in the middle unit, aged between 0-2 years and semi-structured interviews with health professionals working on the unit's patient care. The findings allowed discussing the permanent toy importance as a vital resource to the child's global development during infant hospitalization, contributing to a possible reframing of the traditional model of intervention and care of hospitalized children.
\end{abstract}

Keywords: Games and Toys, Child Development, Hospitalized Child, Occupational Therapy. Autor para correspondência: Valeria Borges Ribeiro Lima, Instituto Nacional de Saúde da Mulher, da Criança e do Adolescente Fernandes
Figueira, Av. Rui Barbosa, 716, Flamengo, Rio de Janeiro, RJ, Brasil, e-mail: valerialima.to@gmail.com

Recebido em Dez. 11, 2014; 1ª Revisão em Fev. 11, 2015; Aceito em Abr. 8, 2015 


\section{Introdução}

O desenvolvimento neuropsicomotor da criança se dá a partir da integração das informações que ela recebe do meio, ou seja, através de suas experiências sensoriais. A integraçáo sensorial é um processo que tem sua fase mais intensa de organização nos primeiros anos de vida e está vinculada ao padrão experiência/aprendizado. Através da integração sensorial, o cérebro recebe, registra e organiza sensaçóes recebidas do corpo e do meio que o circunda, fornecendo a base para executar atividades voluntárias, significativas e funcionais. As alteraçôes de integração sensorial levam à desorganizaçáo dos diferentes sistemas (tato, olfato, paladar, vestibular, visão), desencadeando desordens em diversas áreas, como motora, linguística, cognitiva e social (TAMEZ, 2009; AYRES, 1979).

Segundo Ayres (1979), inicialmente o recém-nascido experimenta sensações, mas não é capaz de dar significado a estas. Conforme passa por contínuas experiências interativas, com sensaçóes de diferentes graus, tipos e combinaçôes de informação sensorial, a criança vai desenvolvendo a capacidade de significação e percepçáo do seu corpo e do mundo. Seu sistema nervoso armazena a percepçáo e o conhecimento adquirido a partir das experiências, produzindo, então, respostas adaptativas à demanda do meio.

Todo ser humano nasce relativamente imaturo e sistemas menos vitais, como o motor, necessitaráo de um tempo pós-parto para sua organização. Tais sistemas, segundo Flehming (2000), não amadurecem espontaneamente, pois este desenvolvimento é facilitado ou inibido pelo padrão genético e pelos estímulos ambientais. Dentre os estímulos ambientais vivenciados pela criança, o brincar destaca-se como uma atividade primordial, presente desde as primeiras interaçóes entre a figura materna e o bebê (WINNICOTT, 1975).

$O$ brincar é a atividade primordial da infância; permite o exercício da fantasia, da imaginação, e vincula-se à constituiçáo do sujeito, devendo ser visto dentro da sua singularidade, com reconhecimento e respeito. É através dele que a criança desenvolve seu potencial criativo e sua personalidade, estabelecendo as bases para as relaçôes sociais e afetivas (REZENDE, 2008; WINNICOTT, 1975).

Brincar se aprende brincando, a partir da repetição e da descoberta; promovem-se, assim, as bases para o aprendizado e o estímulo do desenvolvimento de novas habilidades, para o crescimento e a vida adulta. É uma experiência que envolve o corpo, os objetos, o tempo e o espaço. A criança, a partir da percepção do meio que a envolve e dos movimentos, evolui gradativamente de uma atitude passiva, em relação ao ambiente e às pessoas, para uma atitude ativa e participativa, explorando e interagindo (SANTA ROZA, 1997; REZENDE, 2008; WINNICOTT, 1975).

Segundo Dantas (1998), o brincar é visto como "toda a atividade infantil por excelência", e toda a atividade espontânea da criança tem, a princípio, um fim em si mesma. Desta maneira, o brincar implica nas formas mais primitivas do exercício funcional, que, através da experiência, vai se aperfeiçoando, servindo de base para o desenvolvimento de açóes cada vez mais complexas. Assim, para que a criança consiga utilizar de forma instrumental qualquer habilidade sensorial, motora, cognitiva e psicossocial, ela precisa, antes, brincar com estas instâncias. Isto envolve a motivação e o prazer de explorar novas açôes, a possibilidade de escolhas e decisões, resultando em um agir voluntário e ativo. $\mathrm{O}$ brincar também pode ser aplicado como meio de enfatizar o desenvolvimento e a aquisição de capacidades, funcionando como fonte de aprendizagem e favorecendo o desenvolvimento infantil. O desenvolvimento se refere às capacidades, como a percepção, o movimento e a cognição. Assim, o brincar e o desenvolvimento são conceitos que se relacionam e se entrelaçam todo o tempo. Neste processo, ocupa um importante papel a possibilidade de a criança explorar e brincar com objetos. O objeto, caracterizado na brincadeira, na maioria das vezes, pelo brinquedo, segundo Brougère (2000), tem como valor expressivo a estimulação da brincadeira. Não é definido por uma função específica, uma vez que pode ser manipulado livremente, sem regras ou princípios de utilização. É um objeto que projeta uma imagem em três dimensôes, possibilitando açóes e representaçóes da realidade. Kishimoto (1998) reforça que os brinquedos lidam com o âmbito da reproduçáo da realidade da criança e dos seus contextos. O brincar é um dos principais estímulos normalmente vivenciados pelas crianças e mostra-se primordial para o padrão experiência/aprendizado. As possibilidades de exploração e estimulação são fundamentais para o desenvolvimento infantil, e o contexto hospitalar pode representar um corte neste processo. Quando esta criança está internada ou, muitas vezes, nem chegou a ir para casa desde que nasceu, todo este processo sofre profundas modificaçóes. O processo de hospitalização provoca modificaçóes no cotidiano do paciente e de sua família, alterando rotinas e experiências. Com a internação, a criança é afastada da relação com um cotidiano e com ambientes que normalmente serviriam de estímulo ao seu desenvolvimento 
(casa, escola, relaçóes familiares). Precocemente, passa a vivenciar o sofrimento da doença e suas intervençóes, num cotidiano particular, atrelado às rotinas hospitalares, que pode gerar desconforto físico e emocional (MITRE, 2008).

No caso de crianças de zero a dois anos, período em que ocorre a "fase crítica" de maturação neurofuncional, em que a relação com o ambiente se dá através do sistema sensoriomotor, a hospitalização gera uma alteração dos estímulos que seriam vivenciados naturalmente nos primeiros anos de vida e que são fundamentais para o desenvolvimento neuropsicomotor (LENT, 2004).

Tanto o processo de adoecimento como a própria experiência vivida dentro do hospital podem modificar o desenvolvimento e a qualidade de vida da criança, ao alterar suas relaçóes com o meio. Os estímulos motores e sensoriais são alterados na internação tanto pelas questôes impostas, específicas do quadro clínico, quanto pelas características do meio. A mudança do processo natural do brincar nesse ambiente tende a levar a uma diminuição da integração de todos esses estímulos (SANTA ROZA, 1997; AYRES, 1979; BROUGËRE, 2000).

A relação com o outro é um fator muito importante no processo de brincar; porém, o brinquedo por si só pode funcionar como um estímulo importante ao desenvolvimento infantil, estimulando as capacidades neuromotoras e cognitivas. A interação entre a criança e o brinquedo pode promover a estruturação das noções de espaço, tempo e ritmo, bem como contribuir com a integração do esquema corporal e a construçáo de sua imagem corporal (REZENDE, 2008; PIERCE, 2002; DANTAS, 1998).

Desta forma, a presença de objetos que colaborem com a configuração de um ambiente lúdico no cotidiano de crianças hospitalizadas torna-se fundamental para o estabelecimento de um espaço de exploraçáo e crescimento.

Partindo-se da importância do brincar com objetos para o desenvolvimento global da criança, este artigo investigou o brinquedo permanente como estímulo constante ao desenvolvimento global de crianças internadas em uma Unidade Intermediária de média e alta complexidade, segundo a visão dos profissionais de saúde que trabalham nesta unidade.

\section{Metodologia}

Foi realizada uma pesquisa exploratória de abordagem qualitativa em uma unidade intermediária de um hospital de referencia para a Saúde da Criança. Esta é uma unidade complexa, que atende a uma clientela com um perfil diferenciado de internação pediátrica, com a maior parte das crianças cronicamente adoecidas e dependentes de tecnologia, o que a diferencia de outras unidades intensivas pediátricas. Os sujeitos foram as crianças internadas na unidade e os profissionais de saúde envolvidos no cuidado a estas crianças. Para as crianças, o tamanho da amostra foi o total de crianças de zero a dois anos, internadas no período da pesquisa. A escolha por essa faixa etária se deu por ser uma fase considerada -e denominada - como "período crítico", com grande plasticidade do Sistema Nervoso Central, com maior suscetibilidade de transformaçóes provocadas pelo ambiente externo para a maturação neuronal e, consequentemente, para a evolução neuromotora da criança. Piaget descreve esta fase como período sensoriomotor, caracterizada pela exploraçáo e manipulação de si mesmo, das pessoas à sua volta e dos objetos comuns que o cercam, permeado de importantes experiências sensoriais evolutivas (FLAVELL, 1992). Para os profissionais, foram convidados médicos, enfermeiros, técnicos de enfermagem, fisioterapeutas, fonoaudiólogos, terapeutas ocupacionais, nutricionistas e psicólogos que atuavam diretamente com as crianças.

A pesquisa exploratória foi realizada em duas etapas. A primeira etapa foi composta por observação participante das crianças internadas. Esse tipo de observação, essencial na pesquisa qualitativa, foi escolhido por ser considerado uma técnica que permite a compreensão da realidade vivida pela criança no ambiente pesquisado. Conforme Minayo, Deslandes e Gomes (2007), observação participante pode ser definida como um processo no qual o pesquisador se coloca no lugar de observador da situação social para realizar uma investigação científica, relativizando o espaço social e fazendo um deslocamento para o lugar do sujeito pesquisado, seguindo um plano de observação.

A observação participante contemplou o período de duas semanas investigando o comportamento, a rotina e o cotidiano das crianças internadas na unidade. Os dados coletados foram registrados em um diário de campo, tendo como base: i) o funcionamento da unidade em diferentes horários - quantidade de pessoas, sons, movimento, intervençóes; ii) como a criança era abordada pelas pessoas que circulavam por este espaço; iii) como a criança explorava o ambiente ao seu redor; iv) o que estava no leito destas crianças; v) onde estavam os brinquedos; vi) como era a interação entre a criança e o brinquedo que estava ao seu alcance. A observação de campo ajudou a subsidiar a análise das entrevistas, servindo de contexto para essa discussão. 
A segunda etapa foi composta pela realização de entrevistas semiestruturadas com os profissionais da área de saúde que atuavam de forma sistemática no atendimento aos pacientes, incluindo residentes. O tamanho da amostra foi calculado pelo critério de saturação teórica descrito por Fontanella et al. (2011), mantendo-se o cuidado de selecionar profissionais das diferentes categorias atuantes na unidade. As entrevistas semiestruturadas foram gravadas e transcritas, seguindo-se o seguinte roteiro: i) Caracterização do respondente; ii) Como percebe a presença de brinquedos nos leitos das crianças (interferência na rotina, importância para a criança); iii) Dificuldades que identifica para a presença do brinquedo; iv) Que sugestôes daria para possibilitar a permanência destes brinquedos e por quê. A análise das entrevistas foi realizada a partir da articulação de aspectos temáticos da análise de conteúdo (MINAYO, 2010). Esta técnica de análise possibilitou o conhecimento de questóes além dos conteúdos manifestos analisados. Dessa forma, identificamos as ideias centrais das entrevistas, organizando-as em categorias, de forma a realizar uma síntese das temáticas à luz do referencial teórico sobre "Desenvolvimento global" e do "Brincar como conceito, a função do brinquedo". Inicialmente, foram encontradas 29 unidades temáticas. Em seguida, foi realizada a comparação das unidades temáticas identificadas em nova etapa de releitura, a qual propiciou o agrupamento das mesmas em quatro grandes eixos temáticos: o brinquedo como parte do ambiente; o uso do brinquedo; a criança e a relação com o brinquedo, e brincando com outros objetos.

\section{Resultado e discussão}

\subsection{Caracterização dos sujeitos}

No período da observação participante, estavam internadas cinco crianças com diferentes patologias crônicas, com idades entre seis e 16 meses, e quadros clínicos caracterizados por gravidade e instabilidade de um ou mais sistemas orgânicos. Todas eram traqueostomizadas, dependentes de ventilação mecânica, e necessitavam de monitoração contínua das funçôes vitais e cuidados intensivos. Não houve rotatividade na internação de crianças durante o período observado. A equipe de saúde estava organizada de maneira diversa: as equipes médicas e de enfermagem se dividiam em escalas diárias. Em cada dia, a equipe era composta por um médico diarista, um médico plantonista, um residente médico, uma enfermeira chefe, uma enfermeira diarista e uma plantonista, e duas técnicas de enfermagem diaristas. Os profissionais de outras áreas, como fisioterapeutas, fonoaudiólogos, terapeutas ocupacionais, nutricionistas, psicólogos e outros especialistas, atendiam em rotinas estabelecidas com suas unidades de origem ou sob necessidade da demanda. Das entrevistas, participaram: cinco Médicos; três Enfermeiros; dois Técnicos de Enfermagem; dois Fisioterapeutas (Motor e Respiratório), um Psicólogo, um Terapeuta Ocupacional (Residente) e um Fonoaudiólogo. O tempo de formado dos profissionais variou entre oito meses e 28 anos, com tempo de atuação na unidade variando entre seis meses e nove anos.

Os sujeitos foram identificados com nomes de cores para manter o sigilo. De modo geral, a equipe se mostrou receptiva e interessada em participar do estudo e discutir o "brinquedo permanente" na unidade.

\section{Análise}

Mediante a análise das entrevistas, identificamos quatro eixos temáticos que sintetizam a discussão: o brinquedo como parte do ambiente; o uso do brinquedo; a criança e a relação com o brinquedo, e brincando com outros objetos.

\subsection{O brinquedo como parte do ambiente}

Em geral, os profissionais entrevistados se referiram ao brinquedo como um objeto importante para aproximar a criança de uma rotina normal.

\section{Brinquedo é a tentativa de transformar o mundo numa coisa mais lúdica, no universo mais próximo do que é a realidade infantil (Vermelho).}

Alguns identificavam o brinquedo como marcador da condiçáo de ser criança, independentemente da patologia, entendendo que o brinquedo pertence à criança; logo, deve estar próximo dela.

Porque o brinquedo não é da gente, não é pra
gente trabalhar com as crianças, o brinquedo é
da criança e pra todos ali pra estarem com ela
(Laranja).

Muitos apontaram que a presença do brinquedo junto à criança não atrapalha a rotina hospitalar.

\footnotetext{
Mas eu não vejo dificuldade nenhuma no brinquedo, assim, na prática pra examinar, que dificulte a nossa conduta com as medicaçôes. Eu não vejo nenhuma dificuldade assim à primeira vista (Amarelo).
} 
Porém, alguns enfatizaram que náo podiam ser muitos brinquedos ou estes serem grandes.

Desde que seja uma quantidade limitada, que seja trocado, que o leito não fique cheio de brinquedo, não atrapalha não! (Verde).

Por outro lado, alguns entrevistados declararam que as crianças têm um número reduzido de brinquedos, contextualizando que a presença do brinquedo é maior quando alguns profissionais estão presentes. Nos momentos em que não há intervenção específica de outros profissionais, como fisioterapeutas, terapeutas ocupacionais e a equipe do Programa Saúde e Brincar ${ }^{2}$, a oferta do brinquedo para a criança depende da disponibilidade da equipe presente. A mesma dependência de disponibilidade aparece nos relatos de que a equipe (médica e de enfermagem) brinca às vezes com as crianças.

Mas se não for uma técnica [de enfermagem] que tenha essa preocupação, ás vezes eu acho que a criança fica a manhã inteira sem brinquedo nenhum, entendeu? Até alguém ter a sensibilidade de ir lá e botar um brinquedo (Amarelo).

Eles só têm brinquedos quando alguém oferece. Quando alguém dá na mão da criança, ou de perto, ou quando ele tem condiçôes de pegar sozinho (Verde).

Essa dependência da disponibilidade dos profissionais foi relatada nas entrevistas e observada no campo. Mesmo reconhecendo a importância do brinquedo na vida da criança, independentemente da sua condição de saúde e do contexto ambiental em que se encontra, os profissionais mostram dificuldades em reconhecer a importância de manter o brinquedo próximo à criança. Para parte dos entrevistados, o brinquedo estar guardado no armário ou fora do alcance e do campo visual da criança não é visto como um problema. Diante da dificuldade de o profissional perceber o brincar e o brinquedo como elementos que não podem ser distanciados da criança, foi sugerida, por um entrevistado, a definição de um horário de brincar como rotina diária do setor.

Eu acho que a gente deveria ter uma rotina de "é a hora de brincar mesmo", a gente vai brincar, porque se acontece alguma coisa e vocês não vêm sábado e domingo essas crianças são muito menos estimuladas (Amarelo).

A presença do brinquedo permanente foi vinculada por alguns entrevistados a uma seleção de brinquedos. Essa seleção se daria a partir da adequação do brinquedo para cada idade e pelas precauções e pelos riscos de infecçôes.
O brinquedo, ele precisa ser de acordo com a idade, né? Eu sempre peço pras meninas estagiárias, residentes que estavam aqui, eu pedi que ela fizesse um levantamento dos brinquedos que tinham e quais são aqueles próprios pra aquela idade (Anil).

Já que vai fazer parte do universo da criança, que seja um perfil escolbido, que dê pra limpar a superficie, isso pra gente não levar um risco também, ter um beneficio de um lado não pode trazer um risco maior de infecção (Vermelho).

É importante destacar que, no período das entrevistas, havia uma grande mobilização na unidade quanto às questôes de infecçôes. Tal mobilização se deu após um evento de grande discussão quanto aos brinquedos como possíveis veículos de contágio em internaçóes pediátricas. Tal discussão não é recente e nem foi esgotada. Encontramos esse tópico presente no artigo de Novaes et al. (1997) e em estudos mais recentes, sem haver consenso quanto a essa questáo. $\mathrm{O}$ único ponto em que há concordância é que os brinquedos precisam permitir a devida assepsia.

Quanto à seleção do brinquedo de acordo com a faixa etária, deve-se levar em conta que a criança é um sujeito com suas demandas próprias e singularidades. Partindo-se do princípio de que a hospitalização e as intercorrências clínicas podem provocar um atraso do desenvolvimento neurosensoriomotor e cognitivo da criança, o brinquedo considerado adequado para determinada faixa etária pode não ser o adequado para determinada criança naquele momento.

Nesse sentido, é preciso refletir que o trabalho em saúde, como contextualiza Merhy (2005), é um campo que possui características particulares, por se encontrar no setor de serviços e por tratar de uma realidade que lida diretamente com as necessidades e expectativas de cada sujeito, dentro da sua singularidade. Portanto, a ação assistencial junto a criança e sua família realiza-se através de um trabalho vivo em ato, por meio do qual há o encontro de duas pessoas, atuando uma sobre a outra, em um processo relacional.

A partir desta lógica, o autor classifica as tecnologias que envolvem o trabalho em saúde como: "Tecnologia Leve", aquelas voltadas para "[...] as relaçôes do tipo produção de vínculo, autonomização, acolhimento e gestáo, como uma forma de governar processos de trabalho [...]", e "Tecnologia Dura", aquela que se refere a "[...] equipamentos tecnológicos do tipo máquinas, normas, estruturas organizacionais" (MERHY, 2005, p. 49).

Dentro de um contexto cercado de "Tecnologia Dura", o brinquedo com sua "Tecnologia Leve" 
se vê descaracterizado de sua função no cotidiano dessa criança internada.

Segundo Mitre (2008) e Santa Roza (1997), o contexto hospitalar traz uma ruptura das possibilidades de exploração natural do cotidiano das crianças. A partir da fala dos entrevistados, observamos que eles também percebem essa ruptura. Porém, não parece tấo simples inserir e modificar esse ambiente. $\mathrm{O}$ ambiente hospitalar possui regras, objetos e situaçóes ditados pela própria necessidade. Essas necessidades aparecem nas citaçóes a partir da menção das precauçóes e da importância de se ter poucos brinquedos, de cada vez, nos leitos. A partir disso, podemos pensar que grande parte do desafio está na interlocução das necessidades do ambiente hospitalar com as necessidades lúdicas e de desenvolvimento global das crianças.

A equipe assume uma preocupação com o cuidado da criança, na ação da prática hospitalar, no fazer técnico, o que, de fato, é de extrema importância dentro de todo o contexto. Mas, não se pode deixar de incluir neste processo a condição de ser criança para além da doença. É importante uma assistência hospitalar centrada nas necessidades da criança hospitalizada e não apenas na patologia que carrega em seu corpo; pensar no cotidiano que se pode oferecer para esta criança mesmo em uma situação hospitalar e vê-la como criança que pode brincar, mesmo que este brincar seja diferente do habitual. Afinal, o brincar é singular, construído pela criança a partir do que lhe é oferecido e do meio que se encontra.

A partir do conceito de Dantas (1998), que considera o brincar como toda "atividade espontânea da criança", podemos pensar que o brinquedo e o brincar são recursos primordiais no cotidiano de toda criança. Pacciulio, Carvalho e Pfeifer (2011) afirmam que a criança restrita ao espaço físico hospitalar necessita olhar para objetos, agarrá-los, interagir, de modo que possam girar, apalpar, manusear, brincar e reagir às oportunidades que o ambiente lhe oferece. Assim, pensar o brinquedo como um fator que aproxima a criança do seu contexto natural, como relatam os entrevistados, pareceria um raciocínio lógico.

Quando pensamos em um ambiente habitado por crianças, imaginamos um ambiente colorido, cheio de brinquedos, músicas e estímulos. $\mathrm{O}$ ambiente hospitalar e, principalmente, o ambiente de uma unidade semi-intensiva contrapóem essa visão.

\section{2 $\mathrm{O}$ uso do brinquedo}

Ao relatarem a importância do brinquedo, alguns profissionais referem-se a este como um objeto distrator para as crianças. Porém, muitos demonstram entender que o brinquedo é um estímulo necessário para a criança e chegam a sugerir um rodízio maior dos mesmos. Entrevistados, de diversas categorias, vão além e descrevem o brinquedo como importante para o desenvolvimento da criança, mas relatam que a maior parte da equipe não tem treinamento sobre o brincar, o brinquedo e o desenvolvimento infantil.

Dentro dessa visão, surgiram tópicos, como a necessidade de um espaço/momento de aprendizagem sobre o brincar e o brinquedo, bem como a discussão de questôes sobre os estímulos para o desenvolvimento global infantil.

\begin{abstract}
Acho que uma educação continuada, entender que aquilo é importante, senão acho que ela fica muito limitada a esse desenvolvimento na hora que tem a fisioterapia motora, que tem a terapia ocupacional. [...] vocês não podem tá aqui o tempo inteiro, então acho que a gente tem que pegar um pouco essa função pra gente também, participar desses momentos, né?! (Amarelo).
\end{abstract}

Um entrevistado falou sobre a dificuldade pessoal de brincar com a criança.

Eu não sei como oferecer o brinquedo, obviamente, eu não tenho esse sensor (Índigo).

As falas se repetiram quando se referia à presença da mãe como estímulo ao brincar, porém enfatizando que os familiares não sabem quais os brinquedos adequados para as crianças.

É dificil controlar os familiares porque eles querem trazer coisas demais e nem sempre adequadas e próprias (Violeta).

A partir dessas colocaçóes, observamos que o motivo da importância do brinquedo na unidade ainda não é totalmente claro para a equipe. Da visão de distrator a estímulo para o desenvolvimento motor global, todos percebem sua importância, mas nem sempre conseguem elaborar como e por que o brinquedo é importante.

Diversos autores falam da evolução sensorial como vinculada ao padrão experiência/aprendizado. Refletindo-se esse processo de evolução sensorial, o brinquedo deve ser pensado não só como um distrator ou um estímulo aleatório, mas como um objeto essencial para o adequado desenvolvimento da criança e a prevenção de possíveis alteraçôes (TAMEZ, 2009; AYRES, 1979; SILVA, 2007).

Não podemos esquecer que a criança pequena relaciona-se com o ambiente através de seu sistema sensoriomotor e que a organização cerebral ocorre através das informações trazidas pelo sistema sensorial; assim, o brinquedo, objeto em três dimensões, com 
cores, contrastes, texturas e sabores, pode auxiliar na exploração e no desenvolvimento da criança pequena internada (FLEHMING, 2000; FLAVELL, 1992).

\subsection{A criança e a relação com o brinquedo}

Todos os entrevistados descreveram o brincar e a presença do brinquedo como um estímulo importante para crianças internadas por longos períodos.

Vejo os brinquedos como extremamente importantes, são crianças que são acamadas, que se movimentam às vezes pouco, que não têm a presença da mãe constante, o tempo inteiro, então acho fundamental (Violeta).

Tanto nas entrevistas quanto na observação participante, percebeu-se que quando a criança consegue reclamar, sua necessidade de brincar é mais atendida. Trazem o fato de as crianças ficarem contidas no leito ou com postura inadequada como um fator que atrapalha o brincar e impede o alcance ao brinquedo (motor, visual).

Quando, por exemplo, a criança deixa o brinquedo cair ou vai um pouquinho mais pra longe, como ele está ali preso no leito, ele vai ter dificuldade para buscar este brinquedo (Marrom).

Não adianta ter três brinquedos e tudo longe dela, que você nem sabe aonde tá, que tá enfiado dentro da bolsa, ou que tá dentro daquele armário, ou dentro da gaveta, enfim, é que tem que estar ao alcance da criança (Magenta).

Ao observarem as dificuldades de alcance dos brinquedos pelas crianças e de disponibilidade dos mesmos, afirmam a importância de um recurso para mantê-lo ao alcance delas. Sugerem que este seja um dispositivo esteticamente agradável, simples e seguro.

Acho que a gente deveria pensar em alguma forma de manter o brinquedo ali, sem ser essa forma de ficar prendendo as coisas, ai um prende..., de ser uma coisa especifica pra aquilo (Amarelo).

Para a gente colocar o brinquedo ao alcance da criança, a gente tem que fazer adaptação porque os leitos não tem nenhum dispositivo especifico pra gente colocar o brinquedo (Cinza).

O suporte tinha que ser uma coisa padronizada eu acho. Uma coisa padronizada justamente para ter o brinquedo entendeu? (Magenta).

Nesse contexto, o desenvolvimento de recursos de Tecnologia Assistiva (TA) que possibilitem o uso do brinquedo de forma permanente pode trazer uma solução.

De acordo com Melo e Baranauskas (2006), o conceito de TA refere-se a produtos e serviços que visem a auxiliar e compensar nas limitaçóes funcionais, facilitando e promovendo a possibilidade de uma vida independente, de acordo com seu potencial. $\mathrm{O}$ acesso à TA, portanto, permite o aumento da interaçáo social e, consequentemente, uma melhora tanto na qualidade de vida do indivíduo quanto das pessoas que o cercam (MELO; BARANAUSKAS, 2006; BRACCIALLI, 2007).

\subsection{Brincando com outros objetos}

Este eixo temático trouxe os objetos hospitalares funcionando como brinquedos para as crianças internadas. Devido à presença constante destes materiais utilizados na rotina da unidade, objetos como embalagem de gaze, tubos de aspiração e saquinhos de plásticos tornam-se atraentes, disponíveis e familiares para estas crianças, como relata este profissional:

Ela vai pegar o que ela conhece. O que ela consegue pegar. Toda hora entra uma pessoa da enfermagem fazendo um procedimento. Larga ali um saquinho da sonda de aspiração que ela brinca, faz barulho [...]. É o que ela brinca! Não porque ela não tem interesse pelo brinquedo, é porque não faz parte da dinâmica dela, do dia-a-dia! (Magenta).

É importante destacar que as crianças internadas se encontravam no período sensoriomotor descrito por Piaget. Nesta fase, caracterizada pela intensa exploraçáo corporal e do meio, as crianças brincam com os objetos que as cercam. Portanto, podemos contextualizar que as crianças ali internadas brincam com os objetos comuns à sua volta, que lhe são oferecidos e que fazem parte do seu cotidiano durante a internação (KNOBLOCH; PASSAMANICK, 1987).

A gente ta falando de crianças cronicamente adoecidas então são moradores aqui por longo tempo (Magenta).

Dentro do contexto hospitalar, os objetos hospitalares permeiam o cotidiano da criança, sendo, muitas vezes, os únicos estímulos disponíveis para exploração, substituindo a presença do brinquedo. Brougère (2000) enfatiza a importância do objeto, caracterizado pelo brinquedo, fundamentando-o como um dos meios para se iniciarem a exploração e a brincadeira. O brinquedo composto por uma imagem tridimensional possibilita açôes e representações da realidade. Esse autor destaca, 
ainda, os aspectos materiais e de significaçôes do brinquedo. Nos aspectos materiais, estáo incluídos: tipo de material; forma/desenho; cor; aspecto tátil; aspecto odorífico; ruído e produção de sons. Significações enquadram: representação de uma realidade; modificaçôes induzidas nessa realidade; universo imaginário representado; representação isolada ou que pertence a um universo, e impacto da dimensão funcional. Com cores, formas, texturas, tamanhos e barulhos, o brinquedo pode promover, por si só, fortes estímulos para o desenvolvimento global infantil.

\section{Considerações finais}

Percebe-se que, apesar das dificuldades, existe uma mobilização da equipe em relação à importância de se incluir no cotidiano da criança internada o "brinquedo permanente" como recurso primordial ao desenvolvimento global infantil.

Para isto, torna-se necessário o desenvolvimento de algumas estratégias para permitir a presença desse brinquedo e otimizar seu uso dentro da unidade. Como afirmam Garcia-Schinzarie et al. (2014), é essencial que as instituiçôes de saúde disponibilizem recursos para que as crianças e adolescentes internados tenham suporte nas atividades lúdicas, humanizando a assistência e contribuindo, assim, para o enfrentamento positivo da hospitalização.

O brinquedo e sua função precisam ser reconhecidos na prática da assistência às crianças hospitalizadas como fundamentais para o desenvolvimento de habilidades essenciais para a construçáo do cotidiano infantil. Isso deve ser tão valorizado como qualquer outro procedimento clínico presente no contexto hospitalar. $\mathrm{O}$ brinquedo faz parte da atividade natural da criança, permite o direito e o resgate da condição de ser criança, independentemente do contexto em que se encontra, estimulando, assim, paralelamente, o seu desenvolvimento e o seu bem-estar.

Portanto, é essencial que as equipes que assistem estas crianças conheçam os benefícios do brinquedo e avancem na construção de um conhecimento teórico, pautado na prática diária, para a sistematização da sua presença disponível para toda criança hospitalizada. Com isto, se favorecerá o interesse do agir dessas crianças, estimulando-as a serem ativas, promovendo prazer e satisfação mesmo durante a hospitalização.

A criança, mesmo hospitalizada, ao interagir com o brinquedo e com as pessoas, vivencia situaçóes que possibilitam transformar o espaço, através de brincadeiras, em experiências saudáveis e significativas. Isto possibilita uma aproximação e uma ampliação da vivência num mundo compartilhado, mais próximo de uma realidade social, familiar e lúdica.

Acreditamos que o "brinquedo permanente", trazido nesta pesquisa, precisa fazer parte do ambiente hospitalar infantil, como parte do cuidado.

Para tal, faz-se necessário o esclarecimento da equipe e das famílias quanto às questões relativas ao desenvolvimento infantil e suas relaçóes com o brincar e o brinquedo.

Outro desafio é, pensando na permanência do brinquedo junto à criança no espaço hospitalar, pensar na criação de recursos que possibilitem mantê-lo próximo ao alcance (motor e visual) da criança e que sejam adequados a este ambiente.

\section{Referências}

AYRES, J. Sensory integration and the child. California: WPS, 1979.

BRACCIALLI, L. Tecnologia assistiva: perspectiva de qualidade de vida para pessoas com deficiência. In: VILARTA, R. et al. Qualidade de vida e novas tecnologias. Campinas: IPES, 2007. p. 105-114.

BROUGÈRE, G. Brinquedo e cultura. São Paulo: Cortez, 2000.

DANTAS, H. Brincar e trabalhar. In: KISHIMOTO, T. O brincar e suas teorias. São Paulo: Pioneira Thomson Learning, 1998. p. 111-122.

FLAVELL, J. A psicologia do desenvolvimento de jean piaget. São Paulo: Pioneira, 1992.

FLEHMING, I. Texto e atlas do desenvolvimento normal e seus desvios no lactente: diagnóstico e tratamento precoce do nascimento até o $18^{\circ}$ mês. Sáo Paulo: Atheneu, 2000 .

FONTANELLA, B. et al. Amostragem em pesquisas qualitativas: proposta de procedimentos para constatar saturação teórica. Caderno de Saúde Pública, Rio de Janeiro, v. 27, n. 2, p. 388-394, 2011. http://dx.doi. org/10.1590/S0102-311X2011000200020

GARCIA-SCHINZARI, N. et al. Caixas de histórias como estratégia auxiliar do enfrentamento da hospitalização de crianças e adolescentes com câncer. Cadernos de Terapia Ocupacional da UFSCar, São Carlos, v. 22, n. 3, p. 569-577, 2014. http://dx.doi.org/10.4322/ cto.2014.079.

KISHIMOTO, T. Brinquedo e brincadeira: usos e significações dentro de contextos culturais. In: SANTOS, S. M. P. Brinquedoteca: o lúdico em diferentes contextos. Petrópolis: Vozes, 1998. p. 23-40.

KNOBLOCH, H.; PASSAMANICK, B. Gesell e Amatruda: diagnóstico do desenvolvimento, avaliação e tratamento do desenvolvimento neuropsicológico do lactente e na criança pequena, o normal e o patológico. Rio de Janeiro: Atheneu, 1987. 
LENT, R. Cem bilhões de neurônios: conceitos fundamentais de neurociência. São Paulo: Atheneu, 2004.

MELO, A.; BARANAUSKAS, C. Design inclusivo de sistemas de informação na web. In: SIMPÓSIO SOBRE FATORES HUMANOS EM SISTEMAS COMPUTACIONAIS, 7., 2006, Natal. Anais... Natal: CEIHC, 2006. p. 167-212.

MERHY, E. Saúde: a cartografia do trabalho vivo. São Paulo: Hucitec, 2005.

MINAYO, M. O desafio do conhecimento: pesquisa qualitativa em saúde. São Paulo: Hucitec, 2010.

MINAYO, M.; DESLANDES, S.; GOMES, R. Pesquisa social: teoria, método e criatividade. Petrópolis: Vozes, 2007.

MITRE, R. O Brincar no processo de Humanização da produção de cuidados pediátricos. In: DESLANDES, S. F. Humanização dos cuidados em saúde: conceitos, dilemas e práticas. Rio de Janeiro: Fiocruz, 2008. p. 283300 .

NOVAES, L. et al. Brinquedo pode ser contagioso? Revista Paulista de Pediatria, São Paulo, v. 15, n. 2, p. 77 81, 1997.

PACCIUliO, A.; CARVAlHO, T.; PFEIFER, L. I. Atuação terapêutica ocupacional visando à promoção do desenvolvimento de uma criança em Internação prolon- gada: um estudo de caso. Cadernos de Terapia Ocupacional da UFSCar, São Carlos, v. 19, n. 1, p. 93-99, 2011.

PIERCE, D. O potencial da recreação com objetos para lactentes e crianças na primeira infância em risco de atraso no desenvolvimento. In: FAZIO, L.; PARHAM, L. A recreação na terapia ocupacional pediátrica. São Paulo: Livraria Santos, 2002. p. 86-111.

REZENDE, M. O Brincar e a Intervenção da Terapia Ocupacional. In: DRUMMOND, A. F.; REZENDE, M. Intervençóes da terapia ocupacional. Belo Horizonte: Editora UFMG, 2008. p. 25-44.

SANTA ROZA, E. Um desafio às Regras do Jogo. In: SANTA ROZA, E.; REIS, E. Da análise na infância ao infantil na análise. Rio de Janeiro: Contra Capa Livraria, 1997. p. 161-188.

SILVA, R. Cuidados voltados para o desenvolvimento do bebê pré-termo - uma abordagem prática. In: LANZELOTTE, V. Manual de atenção integral ao desenvolvimento e reabilitação. Rio de Janeiro: Editora Revinter, 2007. p. 3-32.

TAMEZ, R. Intervençôes no cuidado neuropsicomotor do prematuro: UTI Neonatal. Rio de Janeiro: Guanabara Koogan, 2009.

WINNICOTT, D. O brincar e a realidade. Rio de Janeiro: Editora Imago, 1975.

\section{Contribuição dos Autores}

Todas as autoras foram responsáveis pela concepção do texto, organização de fontes e análises, redação do texto e revisão. Todos os autores aprovaram a versão final do artigo.

\section{Notas}

${ }^{1}$ Artigo resultado de pesquisa "O brinquedo permanente em uma unidade intermediária de um hospital de média e alta complexidade”, aprovada pelo Comitê de Ética em Pesquisa em Seres Humanos sob o número 338.383.

${ }^{2}$ A atividade lúdica é o principal recurso terapêutico do Programa de Atenção Integral à Criança Hospitalizada Saúde e Brincar, em que crianças, adolescentes e acompanhantes são convidados a brincar com a equipe do programa. 